\title{
AirXorcist: Raising Awareness About Air Pollution through Narrative Storytelling in Computer Game
}

\author{
AMELIA JATI ROBERT JUPIT*, JIAN WEI FAN \& SARAH SAMSON JUAN \\ Faculty of Computer Science and Information Technology, Universiti Malaysia Sarawak, \\ 94300 Kota Samarahan, Sarawak, Malaysia \\ *Corresponding author: rjajati@unimas.my
}

\begin{abstract}
Air pollution has been on the rise and poses a severe problem that needs the public's attention and action. There is an urgency to raise awareness about air pollution among the people. Computer games can be used as a medium to raise awareness about topics of interest, such as air pollution. We have conducted an online preliminary survey among public members through random sampling to study their awareness level on air pollution and general opinion about a computer game. From the survey, we have found that the public has inaccurate knowledge about air pollution, and some of them were not aware that they have directly contributed to air pollution as well. The survey has also revealed that there is a need for role-playing game (RPG) educative games for the public. Thus, an edutainment RPG computer game entitled "AirXorcist" was developed using the Agile methodology to raise awareness about air pollution. We have also employed a story-telling method in the game to educate players about air pollution. Two tests, namely pre-game and post-game tests, were conducted to determine whether the game can raise public awareness about air pollution. From the analysis, we obtained the t-test statistics $=-7.072$ and $p$ value $=-0.000002$. The result shows sufficient evidence to suggest that the AirXorcist game has successfully helped relay information and raise public awareness about air pollution.
\end{abstract}

Keywords: Air pollution, awareness, computer game, edutainment, story-telling

Copyright: This is an open access article distributed under the terms of the CC-BY-NC-SA (Creative Commons Attribution-NonCommercial-ShareAlike 4.0 International License) which permits unrestricted use, distribution, and reproduction in any medium, for non-commercial purposes, provided the original work of the author(s) is properly cited.

\section{INTRODUCTION}

Air pollutants, which are foreign particles in the atmosphere, are usually the products of both natural and human activities such as volcanic eruption, forest fire, fuel combustion, factory emissions and many more. Household appliances such as cooking stove, oven and air conditioner also contribute toward air pollution by emitting chemical gases to the air. There are also cases where air pollution spread from one place to another, known as transboundary pollution. As an example, Malaysia experiences transboundary haze annually, which is caused by the open biomass burning from its neighbouring country, Indonesia (Othman, Sahani, Mahmud, \& Ahmad, 2014).

According to Nel (2005), over 500,000 deaths caused by toxic particles in polluted air are estimated annually. However, Nel's research has underestimated the magnitude of the effects of air pollution. In 2015, air pollution caused approximately 6.4 million deaths around the world (Landrigan, 2017). Thus, air pollution does contribute to the loss of human life. Most of the time, air pollutants are invisible to the naked eye such as carbon monoxide, sulphur dioxide and nitrogen oxide, which are chemicals emitted from the combustion of fossil fuels (Rothschild, 2019). These air pollutants are harmful to human's health and may cause various kind of cancers and disorders, such as vascular, respiratory, and allergic disorders (Mannucci, Harari, Martinelli, \& Franchini, 2015). However, the invisible chemical gas emissions are hazardous as they are hardly noticeable and may cause death due to their poisonous traits (Walters, 2014).

The air pollution visibility depends on the cause of pollution, which is the air pollutant. To be more precise, there are a lot of factors that affect air visibility such as air temperature, pressure, relative humidity and average wind speed (Hao, Zhang, Yang, Xingtai, \& Handan, 2017). If the visibility in a particular area is high, this indicates that the concentration of air pollutants is low in the area. Even so, these pollutants or gases are 
hazardous to the human body if inhaled excessively. One of the air pollutants from which Malaysians suffer annually is the haze. Haze is a phenomenon when external particles are suspended in the air, causing a disturbance in the human's visibility (World Meteorological Organization, 2017). According to Eldridge (1969), the haze can be transitioned into mist and fog when there is a change in the aerosol distribution of the suspended particles in it. This assertion is probably accurate considering that haze, mist and fog are similarly defined as air with suspended particles. The World Meteorological Organization (2017) has even stated that the visibility arrangement of air in ascending order is fog, mist and haze.

In their study on air pollution in Peninsular Malaysia, Chin, De Pretto, Thuppil, and Ashfold (2019) found that the public has perceived that motor vehicle emission contributes to the primary source of air pollution, followed by industrial emissions and various burning sources. However, only a minority of them chose to reduce their driving time to curb the air pollution that was caused by vehicle emissions. Suffari, Zain, Majid, and Tazilah (2019) emphasised on the need to educate the public, especially school children, on topics like air pollution so that they would be more environmentally aware and responsible for the earth.

In view of the foregoing, there is a need to educate the public so that they are aware of the air pollutants and what they can do to combat and reduce air pollution. In recent years, computer games have been used to educate on various topics even though they are usually made for entertainment purposes (Brezovszky et al., 2019; Hamari \& Keronen, 2017). We have designed and developed 'AirXorcist', an edutainment game to raise awareness about air pollution. Edutainment is a combination of education and entertainment (Aksakal, 2015) where we want to educate the public about air pollution (education) through a computer game (entertainment). Research in edutainment games has used different design approaches such as board games in educating the public about Zakat (Rahman, Sahrir, Zainuddin, \& Khafidz, 2018), augmented reality hidden object game in educating school kindergarten and primary school students as an alternative teaching aid (Keat, Wahid, Murli, \& Hamid, 2018) and pedagogical content for teaching elementary mathematics (Bouzid, Darhmaoui, \& Kaddari, 2017).

Storytelling has been used in games to help learners understand about various topics such as earth sciences, physics and chemistry (Maraffi \& Sacerdoti, 2018). This method can engage learners to see themselves as the protagonist in the game where they can remember the story better and able to respond to the content accordingly (Raybourn, 2014). In a narrative game design, Aarseth (2012) suggested four elements: world, objects, agents and events. The world element refers to a linear (single path of gameplay throughout the game), multicursal (multiple paths of gameplay) or open (players can explore the games freely). The object element refers to avatars, weapons and buildings, for example, that can either be created by players or game developers. The agent element refers to a character with a detailed narrative or a bot that have a simpler narrative. The event element can be a full, playable, multipath or contain no story at all in the game. Following the approach of Aarseth (2012) in designing a narrative game, AirXorcist uses a linear, playable character with a detailed narrative in a full story game. After having embedded the story into the AirXorcist, we then investigated the effectiveness of raising awareness through storytelling in the game using pre-game and post-game tests (Supplementary 1).

We employed the Agile methodology to develop the game for its flexibility in responding to changes in the developmental plan. The Agile methodology comprises seven stages, which are requirement gathering, analysis, design, coding, testing, delivery of partially incremented software and feedback from customer (Sharma, Sarkar, \& Gupta, 2012). Although the methodology was traditionally used for software development, agile methodology has been widely used for game development for its flexibility and practicality (Aurisch, Ahmed, \& Barkat, 2019; Kasurinen, Palacin-Silva, \& Vanhala, 2017). We have incorporated facts about air pollution through narrative storytelling into the game to ensure smooth and seamless gameplay.

\section{METHODOLOGY}

\section{Participants}

In this study, 18 participants were recruited via opportunity sampling during the requirement gathering stage. These participants were recruited through an advertisement posted in Whatsapp groups with the message looking 
for participants to play a computer game on air pollution. Due to the COVID-19 pandemic, we need to adhere to the government's directive for Movement Control Order. As a result of these samplings, there were 18 participants, aged between 13 to 63 years old. Majority of the participants were teenagers (44\% aged 13-18) and young adults (38.9\% aged 19-30). The remaining participants are aged 31-50 years old (11.1\%) and above 51 years old $(5.6 \%)$

\section{Material}

AirXorcist is a 2-dimensional (2-D) action and platform game for computers. The game uses a narrative storytelling method to relay information about air pollution to its players. Examples of this information include "the smoke produced by closed burning is polluting the air" and "the air conditioner pollutes the air if there is a leak in the refrigeration pipe". This storytelling approach informs players on the objective of each of the game stage that they are playing. From this method, players would know what to do to clear the game stage. Moreover, the storytelling approach can engage players in the game and sustain their participation so that they can continue engaging with the game (Jupit, Minoi, Arnab, \& Wee, 2012).

AirXorcist uses "hack and slash" for its action element. "Hack and slash" refers to a combat style that utilizes hand-to-hand combat, primarily with "slashing" weapons such as swords as opposed to gun (Thomas, 2015). The game was developed using Unity, a popular game engine for 2D and 3D multiplatform games. The Audacity software was used to edit sounds while PaintTool SAI and Paint software were used to design the 2D sprites for the images used in the game. After we have gathered the requirements as outlined in the agile methodology, we then design the game flowchart (Figure 1) to visualise the flow of the gameplay in AirXorcist.

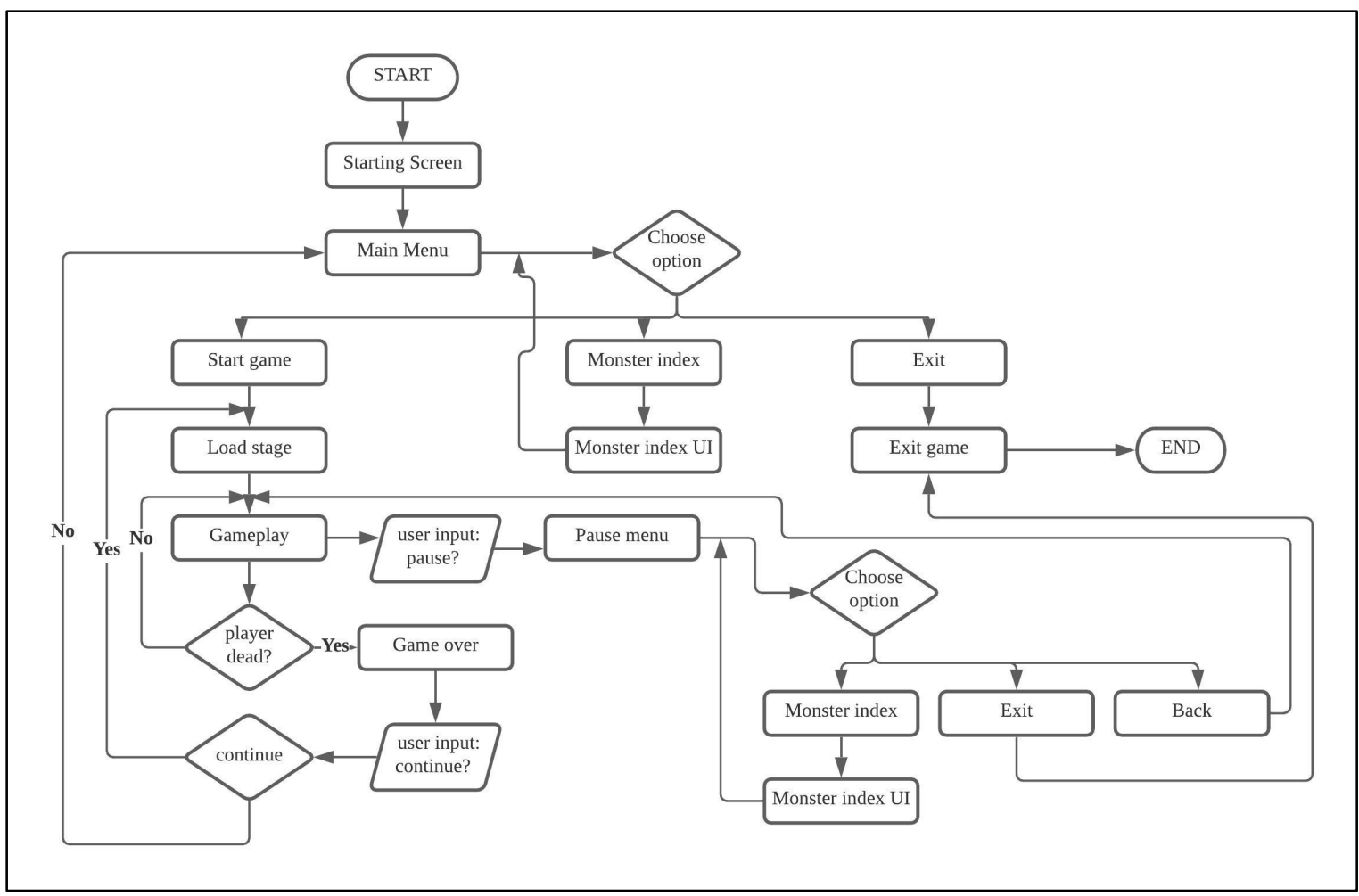

Figure 1. Game design for AirXorcist overall gameplay

Figure 2 shows the general flow of the game stages during the AirXorcist gameplay after the players select a stage. At the starting of the stage, a prologue story event is used to narrate the game's story and objectives to the players. After the prologue ended, the players are to explore each game stage to search and defeat the boss monster, a computer-controlled character stronger than the usual opponents. The players will need to hack and slash the monster while the health bar is still available (Figure 3). Whenever the players through their character 
gets wounded, its health bar will decrease. If the health bar is empty, the players lose the battle and consequently the game. When the players defeat the boss, the epilogue story will be displayed to conclude the story of the stage, which also signifies that the players have cleared the game stage.

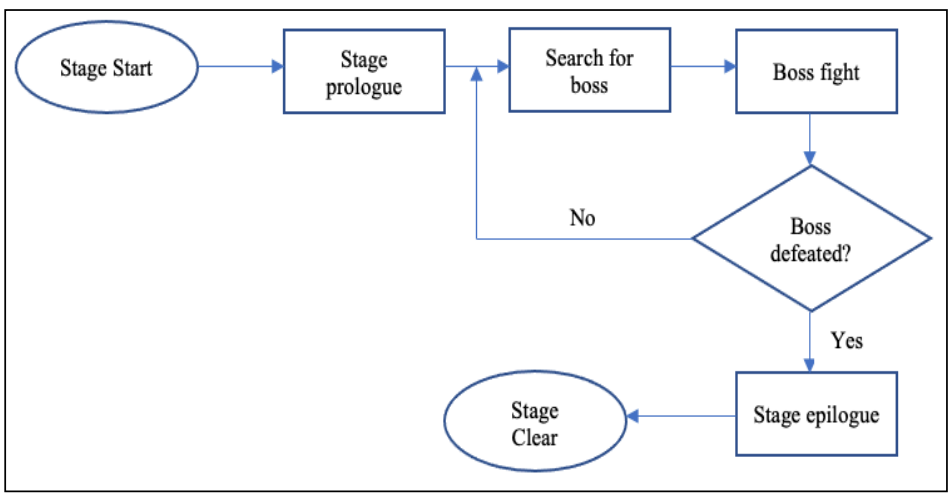

Figure 2. Game flow of the stage in which players will fight with the boss monster.

In the first stage of the game, the players enter Saniedion Woods, an unexplored area that is said to have a deplorable air condition. There, the AirXorcist discovers an inhabited house. The air around the house appears to be heavily polluted. Suspecting that the house is the source of the haze, the AirXorcist ventures into the house only to discover that the interior is swarmed with pollutant monsters. These monsters take the form of home appliances such as the refrigerator and cooking stove. The house owner forgot to switch off these appliances before abandoning it, which caused the appliances to turn into pollutant monsters.

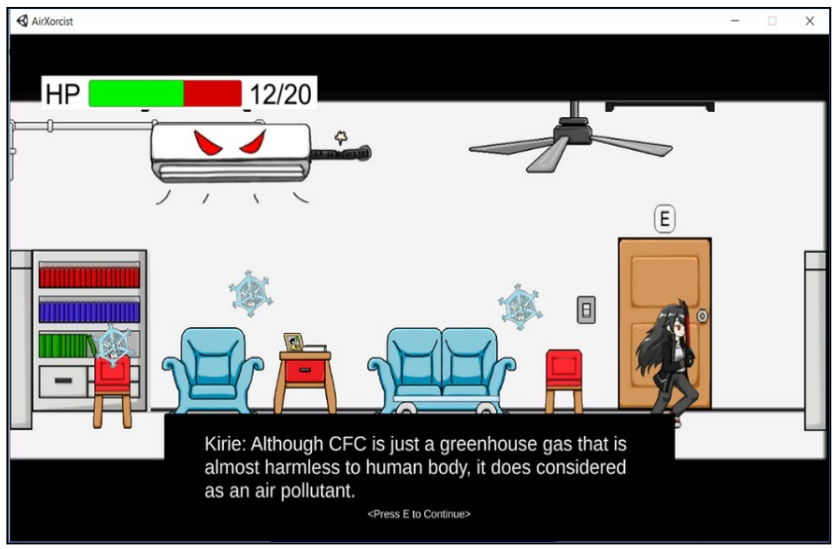

Figure 3. The player exploring the house with a pollutant monster that released snowflakes in the house. There is another monster with a firewood appearance, that is probably caused by the owner who did not put out the fire. While exploring the house, the AirXorcist discovers an air conditioner that has turned into a pollutant monster. The monster grows too powerful and releases cold air in the form of snowflakes. After killing the air conditioner monster, the AirXorcist realises that the air conditioner monster is not the cause of the haze. Thus, the AirXorcist ventures deeper into the woods in search of the real cause of the haze.

In the second stage, the AirXorcist encounters more air pollutant monsters as she ventures deeper into the woods, Hazferr Kingdom. There, the monsters look like land vehicles, specifically cars and motorcycles. There is also a cow-like monster that produces gas-like pollutant through its farts. Finally, the AirXorcist discovers a powerful tree monster that is burning continuously. This monster is a cursed tree which is then transformed into a monster (Figure 4). The AirXorcist then starts to fight with the tree monster and is able to defeat it. Once the tree monster is destroyed, the heavy smoke around the area begin to clear, and the curse of the burning tree is 
lifted. Thus, Hazferr Kingdom regains its beautiful nature, and its citizens become healthy again with the haze gone. The AirXorcist continues with her journey to eradicate air pollution in other parts of the world. To further educate players about air pollution, we have added a monster index in the game to display details about the monsters which were designed based on air pollutionrelated facts.

\section{Procedure}

Before the study started, participants were asked to read and sign a consent form detailing the purpose, procedure, risk and confidentiality of the study. Participants were assured that they can withdraw from the study at any time and to withdraw their permission on the collected personal data. After having signed the form, participants then proceed to a pre-test that will test their knowledge about air pollution. After having answered the questions in the test, participants then play the game "AirXorcist" for approximately 10 minutes. Then, the participants proceed to answer air polluted related questions in the post-test. The questions in both tests comprised both common and uncommon knowledge as well as misinterpreted information about air pollution.

\section{RESULTS}

There are nine questions in each test, which means the maximum score in each test is nine. The participants' scores from both pre- and post-tests are then collected by summing up the total correct answers individually. These scores were then used to determine the effectiveness of the game AirXorcist in raising awareness about air pollution. The scores were recorded and tabulated, as shown in Table 1.

As the data is dependent, a paired sample t-test was used to analyse the data to determine whether there is a difference between the pre- and post-game test scores. At $95 \%$ confidence interval for the difference, $\mu$, is given by $\overline{x_{d}} \pm \mathrm{E}$,

$$
\text { where } \mathrm{E}=\mathrm{t}\left(1-\frac{\alpha}{2} ; \mathrm{n}-1\right)\left(\frac{s_{d}}{\sqrt{n}}\right), \alpha=0.05 \text { and } \mathrm{n}=18 \text {. }
$$

From the table, the critical value $\mathrm{t}=2.110$ for the degree of freedom, $\mathrm{df}=17$. The interval can be obtained as:

$$
\begin{gathered}
\mu=-3.389 \pm 2.110\left(\frac{2.033}{\sqrt{18}}\right) \\
\mu=(-4.4,-2.378)
\end{gathered}
$$

The hypothesis testing was then carried out with having the hypothesis as:

Null hypothesis; $H_{0}: \mu=0$ (The score shows no improvement after playing AirXorcist) Alternative hypothesis; $H_{1}: \mu \neq 0$ (The score shows improvement after playing AirXorcist)

Table 2 shows the results of calculations. From the table, the value of the $t$-statistic, $t=-7.072$ and $p$ value $=0.000002$. Since the $p$-value is less than significance level $(\alpha=0.05)$, the null hypothesis is rejected. This shows sufficient evidence that the AirXorcist game has improved the participants' scores. This also means that AirXorcist has indeed successfully helped to relay information and raise public awareness about air pollution. Note that the confidence interval which is $(-4.4,-0.288)$ as previously calculated. This shows that there is sufficient evidence to support that the mean difference does not lie in the interval. 


\section{DISCUSSION}

This study used the narrative storytelling approach in the game AirXorcist to create awareness among the public about air pollution. Using the narrative storytelling approach in games is not new and has been used in mainstream games, for example, Assassin Creed, Mass Effect, The Witcher and Final Fantasy series. Researchers have used games to educate the public about topics of interests such as bullying (Calvo-Morata, Alonso-Fernández, Freire, Martínez-Ortiz, \& Fernández-Manjón, 2020), environmental (Gardeli et al., 2017) and cross-cultural awareness (Jupit, Minoi, Arnab, \& Yeao, 2011; Jupit et al., 2012; Maraffi \& Sacerdoti, 2018).

Understanding how storytelling in games can help in raising awareness about topics of interest is essential to engage learners not just for the entertainment aspect but learners' education as well. The effect of this engagement can be seen in the results, where there is a difference in the mean scores before and after playing the AirXorcist game. Even though AirXorcist is a simple game that centred on the issue of air pollution, this shows that games can be instrumental in educating and engaging learners. One participant suggested for more facts on air pollution to be added into the game. The suggestion showed that the learner wanted to continue engaging with the game and to learn more of the topic. Schoenau-Fog $(2011 ; 2014)$ described those who wanted to continue engaging with the game are enthusiastic about their gameplay and that this contributed to a successful gameplay experience. Considering that storytelling in games can create awareness about topics of interest, investigating players' recounted experiences using qualitative methods such as interviews will add value and knowledge in further understanding of narrative storytelling in games.

Table 1. Pre- and post- test scores.

\begin{tabular}{cccc}
\hline Participants, Pn & Pre-game & Post-game & Difference, $\overline{x_{d}}$ \\
\hline P1 & 5 & 9 & -4 \\
P2 & 4 & 6 & -2 \\
P3 & 4 & 9 & -5 \\
P4 & 2 & 9 & -7 \\
P5 & 5 & 7 & -2 \\
P6 & 6 & 5 & 1 \\
P7 & 6 & 9 & -3 \\
P8 & 5 & 9 & -4 \\
P9 & 5 & 9 & -4 \\
P10 & 4 & 8 & -4 \\
P11 & 5 & 5 & 0 \\
P12 & 2 & 9 & -7 \\
P13 & 5 & 8 & -3 \\
P14 & 5 & 9 & -4 \\
P15 & 3 & 6 & -3 \\
P16 & 2 & 5 & -3 \\
P17 & 3 & 8 & -5 \\
P18 & 6 & 8 & -2 \\
\hline Mean Scores & 4.278 & 7.667 & -3.389 \\
\hline
\end{tabular}


Table 2. Paired samples test.

\begin{tabular}{|c|c|c|c|c|c|c|c|c|c|}
\hline & & & Paired & Difference & & & & & \\
\hline & & Mean & $\begin{array}{c}\text { Std. } \\
\text { Deviation, sd }\end{array}$ & $\begin{array}{c}\text { Std. Error } \\
\text { Mean }\end{array}$ & $\begin{array}{r}9 \\
\text { Con } \\
\text { Interv } \\
\text { Diff } \\
\end{array}$ & $\begin{array}{l}\% \\
\text { dence } \\
1 \text { of the } \\
\text { rence }\end{array}$ & $\mathrm{t}$ & $\mathrm{df}$ & $\begin{array}{c}\text { Sig. } \\
\text { (2-tailed) }\end{array}$ \\
\hline & & & & & Lower & Upper & & & \\
\hline Pair 1 & $\begin{array}{l}\text { Pre-test - } \\
\text { post-test }\end{array}$ & -3.389 & 2.033 & 0.479 & -4.4 & -2.378 & -7.072 & 17 & 0.000002 \\
\hline
\end{tabular}

\section{CONCLUSION}

This paper investigated the effectiveness of using storytelling in games about a topic of interest, air pollution. Through the method of storytelling, the paper reported that games could be a useful tool to create and promote awareness among the public on topics that are of interest. By interweaving air pollution facts into the storyline, games do help to engage learners to learn about air pollution facts while enjoying themselves. There is room for further design and development to promote learners' continual engagement with the game in which more levels can be added to incorporate more air pollution facts. This future work is vital for further research on usability and validation as we wanted to involve various stakeholders such as schools and community in using games for education.

\section{ACKNOWLEDGEMENTS}

The authors would like to thank the staff and students of Faculty of Computer Science and Information Technology, Universiti Malaysia Sarawak and the participants of AirXorcist for their assistance with the game.

\section{REFERENCES}

Aarseth, E. (2012). A narrative theory of games. Proceedings of The International Conference on The Foundations of Digital Games (pp. 129-133).

Aksakal, N. (2015). Theoretical view to the approach of the edutainment. Procedia-Social and Behavioral Sciences, 186, 1232-1239.

Aurisch, R., Ahmed, M., \& Barkat, A. (2019). An outlook at Agile methodologies for the independent games developer. International Journal of Computers and Applications, 1-7.

Bouzid, T., Darhmaoui, H., \& Kaddari, F. (2017). Promoting elementary mathematics learning through digital games: Creation, implementation and evaluation of an edutainment game to promote basic mathematical operations. In Proceedings of the 2nd international Conference on Big Data, Cloud and Applications (pp. $1-4)$.

Brezovszky, B., McMullen, J., Veermans, K., Hannula-Sormunen, M. M., Rodríguez-Aflecht, G., Pongsakdi, N., Laakkonen, E., \& Lehtinen, E. (2019). Effects of a mathematics game-based learning environment on primary school students' adaptive number knowledge. Computers \& Education, 128, 63-74.

Calvo-Morata, A., Alonso-Fernández, C., Freire, M., Martínez-Ortiz, I., \& Fernández-Manjón, B. (2020). Serious games to prevent and detect bullying and cyberbullying: A systematic serious games and literature review. Computers \& Education, 103958. doi:10.1016/j.compedu.2020.103958

Chin Y. S. J., De Pretto L., Thuppil, V., \& Ashfold, M. J. (2019). Public awareness and support for environmental protection - A focus on air pollution in Peninsular Malaysia. PLOS ONE, 14(3), e0212206. https://doi.org/10.1371/journal.pone.0212206

Eldridge, R. G. (1969). Mist - the transition from haze to fog. Bulletin of the American Meteorological Society, 50(6), 422-427. doi: 10.1175/1520-0477-50.6.422

Gardeli, A., Vosinakis, S., Englezos, K., Mavroudi, D., Stratis, M., \& Stavrakis, M. (2017). A week without plastic bags: Creating games and interactive products for environmental awareness. In International Conference on Advances in Computer Entertainment (pp. 128-138). Springer, Cham.

Hamari, J., \& Keronen, L. (2017). Why do people play games? A meta-analysis. International Journal of Information Management, 37(3), 125-141. 
Hao, J., Zhang, G., Yang, Y., Xingtai, M. B., \& Handan, M. B. (2017). The characteristics of atmospheric visibility and influencing factors. Journal of Arid Land Resources and Environment, 31.

Jupit, A. J. R., Minoi, J., Arnab, S., \& Yeao, A. (2011). Cross-cultural awareness in game-based learning using a TPACK approach. In The 10th International Workshop on Internationalisation of Products and Systems.

Jupit, A. J. R., Minoi, J-L., Arnab, S., \& Wee, A. Y. (2012). Story-telling and narrative methods with localised content to preserve knowledge. In P. Felicia (Ed). Proceedings of The 6th European Conference on Games Based Learning - ECGBL 2012 (pp. 210-218). Academic Publishing International.

Kasurinen, J., Palacin-Silva, M., \& Vanhala, E. (2017). What concerns game developers? A study on game development processes, sustainability and metrics. In 2017 IEEE/ACM 8th Workshop on Emerging Trends in Software Metrics (WETSoM) (pp. 15-21). IEEE.

Keat, O. Y. B., Wahid, N., Murli, N., \& Hamid, R. A. (2018). Augmented Reality to Induce Enjoyment in Edutainment Mobile Game. JOIV: International Journal on Informatics Visualization, 2(3-2), 188-193.

Landrigan, P. J. (2017). Air pollution and health. The Lancet Public Health, 2(1), e4-e5.

Mannucci, P. M., Harari, S., Martinelli, I., \& Franchini, M. (2015). Effects on health of air pollution: a narrative review. Internal and Emergency Medicine, 10(6), 657-662.

Maraffi, S., \& Sacerdoti, F. M. (2018). Innovative Digital Games to Improve Science Education through Storytelling, Mystery and Myth. British DiGRA.

Nel, A. (2005). Air pollution-related illness: effects of particles. Science, 308(5723), 804-806. doi: 10.1126/science.1108752

Othman, J., Sahani, M., Mahmud, M., \& Ahmad, M. K. S. (2014). Transboundary smoke haze pollution in Malaysia: Inpatient health impacts and economic valuation. Environmental Pollution, 189, 194-201.

Rahman, A. A., Sahrir, M. S., Zainuddin, N., \& Khafidz, H. A. (2018). An evaluation of Global Zakat Game (GZG) as edutainment board game in enhancing Zakat education in Malaysia. Educational Research and Reviews, 13(5), 166-172.

Raybourn, E. M. (2014). A new paradigm for serious games: Transmedia learning for more effective training and education. Journal of Computational Science, 5(3), 471-481.

Rothschild, R. E. (2019). Poisonous Skies: Acid Rain and the Globalization of Pollution. University of Chicago Press.

Schoenau-Fog, H. (2011). Hooked! - Evaluating engagement as continuation desire in interactive narratives. In: International Conference on Interactive Digital Storytelling (pp. 219-230). Springer, Berlin, Heidelberg.

Schoenau-Fog, H. (2014). The Player Engagement Process - An Exploration of Continuation Desire in Digital Games. In DiGRA 2011 Conference: Think Design Play, 6, 1-18. isbn: 9781119055006. doi: 10.1002/ 9781119055006.ch13. url:http://www.digra.org/wp-content/uploads/digital-library/11307.06025.pdf

Sharma, S., Sarkar, D., \& Gupta, D. (2012). Agile processes and methodologies: A conceptual study. International Journal on Computer Science and Engineering, 4(5), 892-898.

Suffari, N. F., Zain, M., Majid, M., \& Tazilah, M. D. A. K. (2019). A Conceptual Study of Social Responsibility Awareness and Practices among School Children. International Journal of Business and Technology Management, 1(1), 1-17.

Thomas, C. (2015). The design, implementation, and incorporation of" hack and slash" animation into the unreal development kit. All Theses, 2270.

Walters, R. (2014). Air pollution and invisible violence. In Invisible Crimes and Social Harms (pp. 142-160). Palgrave Macmillan, London. doi: 10.1057/9781137347824_8

World Meteorological Organization (2017). Manual on Codes (WMO-No. 306), Volume I.1, Part A Alphanumeric Codes. (2011 ed.). 